\title{
Hot Water Epilepsy
}

\author{
WANDA SZYMONOWICZ AND KEITH L. MELOFF
}

SUMMARY: A case of hot water epilepsy is presented and the literature on the subject is reviewed. The data show that hot water epilepsy is a benign form of reflex epilepsy occurring mainly in children. Males are affected more than females. The triggering stimulus is immersion in hot water (over $\left.37^{\circ} \mathrm{C}\right)$. The scizare is usually psychomotor, although generalized convilsions may occar. The EEG findings indicate that the abnormality lies in the temporal lobe.

RÉSUMÉ: Un cas d'epilepsie provoque par limmersion du corps dans l'eau chande est presente et les auteurs etablissent une revue de la litterature sur ce sujet. Les données indiquent que ce type d'epilepsie est une forme benigne d'epilepsie sensorielle que se trowve plutôt chez les enfants. Les garcons sont atteints plus souvents que les filles. Le facteur declanchant est l'immersion du corps dans l'eau chaude (plus de $37^{\circ} \mathrm{C}$ ). Les convulsions psychomoteurs sont les plas frequentes mais on rencontre aussi des convulsions grand mals. Les données electroencephalographiques indiquent que l'anomalie est dans le lobe temporal.

From the Division of Neurology, Hospital For Sick Children, Toronto, Ontario, Canada.

Reprint requests to: Keith L. Meloff, M.D., Division of Neurology. Hospital For Sick Children, 555 University Avenue, Toronto, Ontario M5G IX8, Canada.

\section{INTRODUCTION}

In 1833 Marshall Hall first suggested the concept of reflex epilepsy. Since then, many authors have reported cases where seizures were induced by sensations, including visual, auditory, somatic, olfactory, gustatory and visceral stimuli (Daube 1965). The critical stimulus may be simple or complex, as in reading (Bingel, 1958) or arithmetical (Ingvar and Nyman, 1962) epilepsy.

Epilepsy precipitated by immersion in hot water has been reported by Allen (1945), Mofenson et al. (1965), Mani et al. (1968, 1972, 1974), Keipert (1969), Budai and Popescu-Tismana (1970), Stinsman and Ursing (1971), Onuma et al. (1972) and Subrahmanyam (1972). However, this type of epilepsy has been regarded as rare and many of the authors were not aware of other case reports. We present a case of hot water immersion epilepsy and review and discuss the characteristics of this form of sensoryprecipitated epilepsy.

\section{CASE REPORT}

A male infant was first seen at the age of 11 months. He was born to Guatemalan parents after a full term pregnancy. Labor and delivery were normal. There were no prenatal or perinatal problems. There was no family history of epilepsy. Both parents and an older male sibling were in good health.

At seven months, he began to have seizures in his sleep during which his eyes rolled upwards and his arms jerked. All investigations at eleven months were normal, including hematology, chemistry, metabolic screen of urine, skull $x$-rays and waking, drowsy and sleep electroencephalograms. Both the physical and neurological examina- tions were normal. Initially, the child was treated with phenobarbital. Later, diphenylhydantoin was added.

At the age of eighteen months the parents reported that he had seizures only when he had a bath. A few seconds after being put in the bath, he laughed in a strange way, stared straight ahead and then became limp. Each episode lasted about fifteen seconds. Two months later there was a change in the seizure pattern. While in the bath, and only after hot water was poured over his head and shoulders, he laughed, ground his teeth, rolled his eyes to the right and the left side of his mouth twitched. Then, he fell back limp, became stiff and his right side jerked. Afterwards he was drowsy. Each seizure lasted one to three minutes.

He was re-admitted for investigation. Lead, calcium and phosphorus levels, CSF examination and metabolic screen were normal. Electroencephalograms, skull x-rays, brain scan and CAT Scan were nor. mal. Examination revealed slightly increased deep tendon reflexes and a mild speech delay. He was discharged on a dose of diphenylhydantoin sufficient to maintain a blood level in the therapeutic range $(10-20 \mu \mathrm{g} / \mathrm{ml})$.

Despite anticonvulsant therapy, he continued to have these seizures. At twenty-eight months he began to have focal right-sided seizures as well, either during sleep or upon awakening. An interictal EEG showed slightly slower and higher voltages in the left post central region. At thirty months he had four grand mal seizures with a high fever $\left(40^{\circ} \mathrm{C}\right)$. An electroencephalogram at that time showed a poorly defined disturbance in the left post central region. 
During the next seven months he continued to have psychomotor convulsions upon immersion in hot water and benign focal epileptic attacks during sleep or upon awakening. In November, 1975, he was admitted for multiple EEG's in order to demonstrate the site of central nervous system irritability and, perhaps, provide a more rational basis for treatment. An EEG performed while hot wet towels were applied to his body showed a slight disturbance in the left post central region and induced no seizure. A Brevital (methohexital) EEG showed a spike focus arising from the left anteromid-temporal region. He was discharged on diphenylhydantoin 50 mgs. t.i.d. and at last follow-up, his sensory-precipitated seizures were reduced to two per month.

\section{DISCUSSION}

This type of reflex epilepsy has been reported. Allen (1945), Mofenson et al. (1965), Keipert (1969), Stensman and Ursing (1971) and Onuma et al. (1972) reported one case each; Budai and Popescu-
Tismana (1970) reported three cases; Subrahmanyam (1972) reported twenty-six cases and Mani et al. (1968, 1972, 1974) reported 108 cases. All of the authors stated that hot water immersion was the singular and specific triggering stimulus. The temperature of the water required to induce an attack was variously reported as $37.2^{\circ}-37.8^{\circ} \mathrm{C}$ (Mofenson et al. 1965), $40^{\circ}-50^{\circ} \mathrm{C}$ (Mani et al., 1968, 1972, 1974), $37.5^{\circ} \mathrm{C}$ (Stensman and Ursing, 1971), $39^{\circ} \mathrm{C}$ (Onuma et al., 1972), $45^{\circ} \mathrm{C}$ (Subrahmanyam, 1972) and normal bath temperature (Allen, 1945; Keipert, 1969; Budai and PopescuTismana, 1970). Some used this information to prevent further seizures by bathing the child in lukewarm water or by sponge-bathing (Mofenson et al., 1965; Mani et al., 1968; Keipert, 1969; Subrahmanyam, 1972). Others showed that cold water, tepid water, hot water towels, saunas and hot air did not precipitate a seizure (Mani et al., 1968, 1972, 1974; Stensman and Ursing, 1971; Onuma et al., 1972; Subrahmanyam, 1972). In our case, only hot water $\left(37^{\circ}-38^{\circ} \mathrm{C}\right)$ was an effective stimulus. Cold water, lukewarm water, sponging or application of hot wet towels did not trigger a convulsion.

Since heat seems to be an important precipitating factor, an increased incidence of febrile convulsions might be expected. Mani et al. (1972) reported an incidence of $11 \%$ and Subrahmanyam (1972) an incidence of $15 \%$. All of the other authors reported no febrile seizures. In this case, febrile seizures occurred during one upper respiratory tract infection. However, the incidence of febrile convulsions is $30 \%$ in children with a diagnosis of seizures (Meloff, 1971; Millichap, 1968). Therefore, the association of febrile seizures with hot water immersion epilepsy is not greater than one would predict.

It appears evident that the specific triggering stimulus is a complex one, involving the combination of the temperature and tactile stimuli produced by contact with hot water.

Cases of epilepsy have been reported where emotional stimuli have been able to trigger seizures (Allen,

TABLE I

FEATURES OF THE SEIZURE

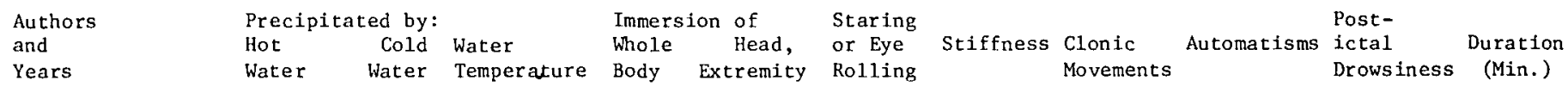

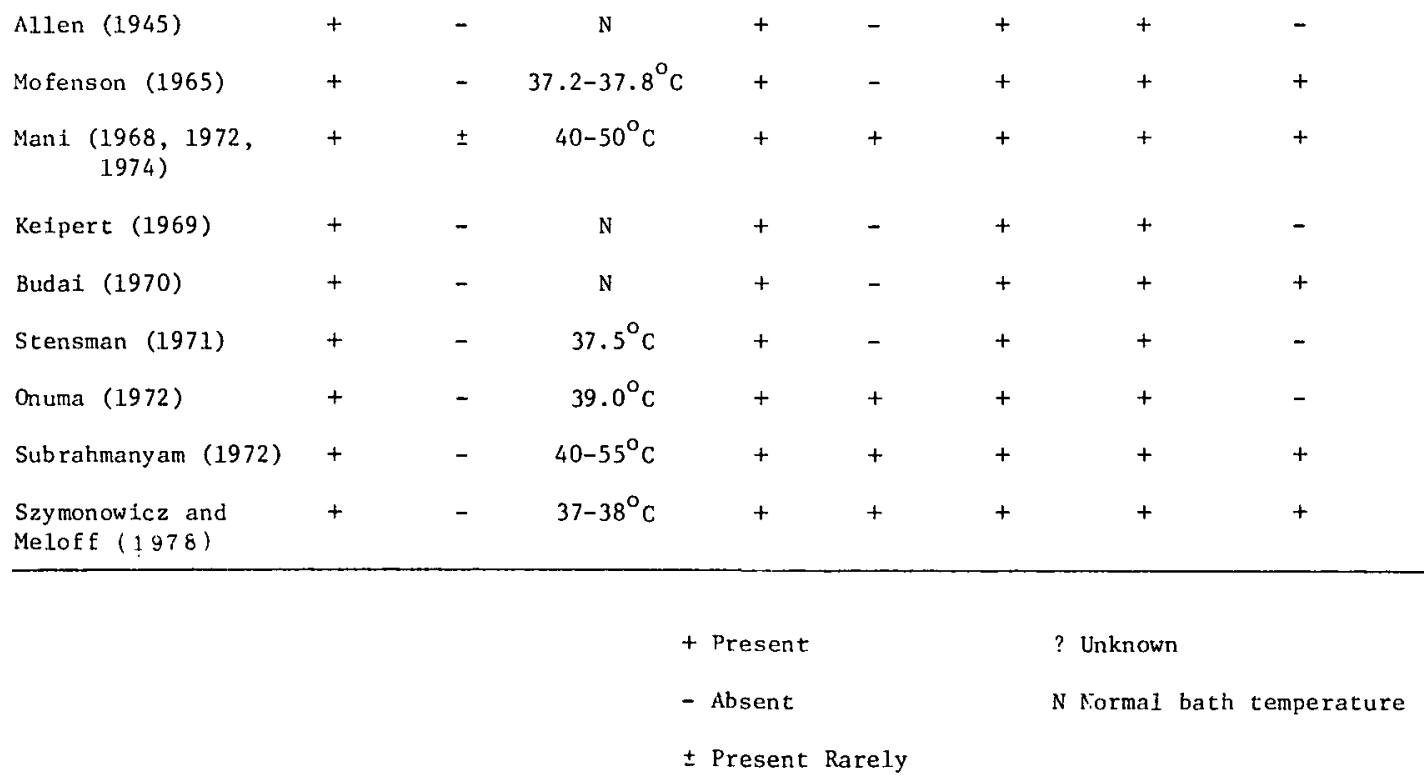


1956). Several authors (Mani et al., 1968; Keipert, 1969; Stensman and Ursing, 1971) reported no evidence of emotional disturbance in their cases. No description of the seizure suggested a breath-holding spell. Our patient enjoyed taking baths and showed no fear of being immersed in water. To date he has not demonstrated any behavior problems. We believe we have ruled out breathholding spells and hysteria in our differential diagnosis.

The underlying neural mechanism remains obscure. The EEG findings and the features of the seizures indicate temporal lobe involvement (Tables I and II). Budai and PopescuTismana (1970), Stensman and Ursing (1971) and Onuma et al. (1972) found EEG abnormalities in the anterotemporal region and strong evidence of a focus only in the ictal EEG. In case 2, Budai and Popescu-Tismana (1970) obtained EEG confirmation only when they used intravenous hexobarbitone. In our case, drowsy and sleeping EEGs, several interictal EEGs and an EEG done during application of hot wet towels showed little abnormality. However, an EEG obtained during sleep induction with intravenous methohexital (Brietal) revealed a temporal lobe focus not

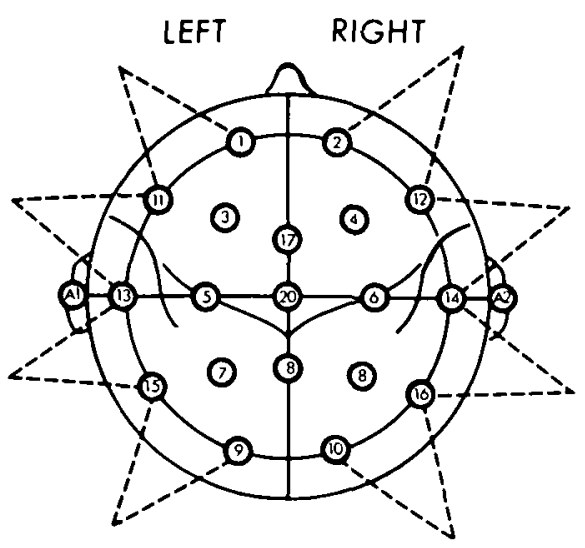

Figure IA-Electrode placement.

apparent previously (Figure 1). EEG activation of epileptic foci by methohexital in other types of psychomotor epilepsy has been well established (Wilder, 1971; Gumbert and Paul, 1971: Hansotia and Berendes, 1972), although some argue that it is not as effective as natural sleep (Sherwin and Hooge. 1973). The rest of the authors obtained interictal EEGs that were either normal or that showed some diffuse paroxysmal activity. In this type of reflex epilepsy, as in other types of psychomotor epilepsy, identification of a temporal lobe focus is not an easy lask unless provocative methods (ie. hot water bath. methohexital activation) are used.

A comparison of previous case reports and the present case reveals several common characteristics of hot water epilepsy (Tables I and II). Males are affected more often than females. The disorder begins in childhood with peaks between 6 months and 2 years and between 6 and 10 years. The precipitating stimulus is immersion in hot water $\left(37^{\circ}-50^{\circ} \mathrm{C}\right)$ for a few seconds or minutes. The seizure is usually psychomotor although generalized convulsions may also occur.

Neurological and physical examinations are normal. An EEG may

TABLE II

CHARACTERISTICS OF HOT WATER EPILEPSY

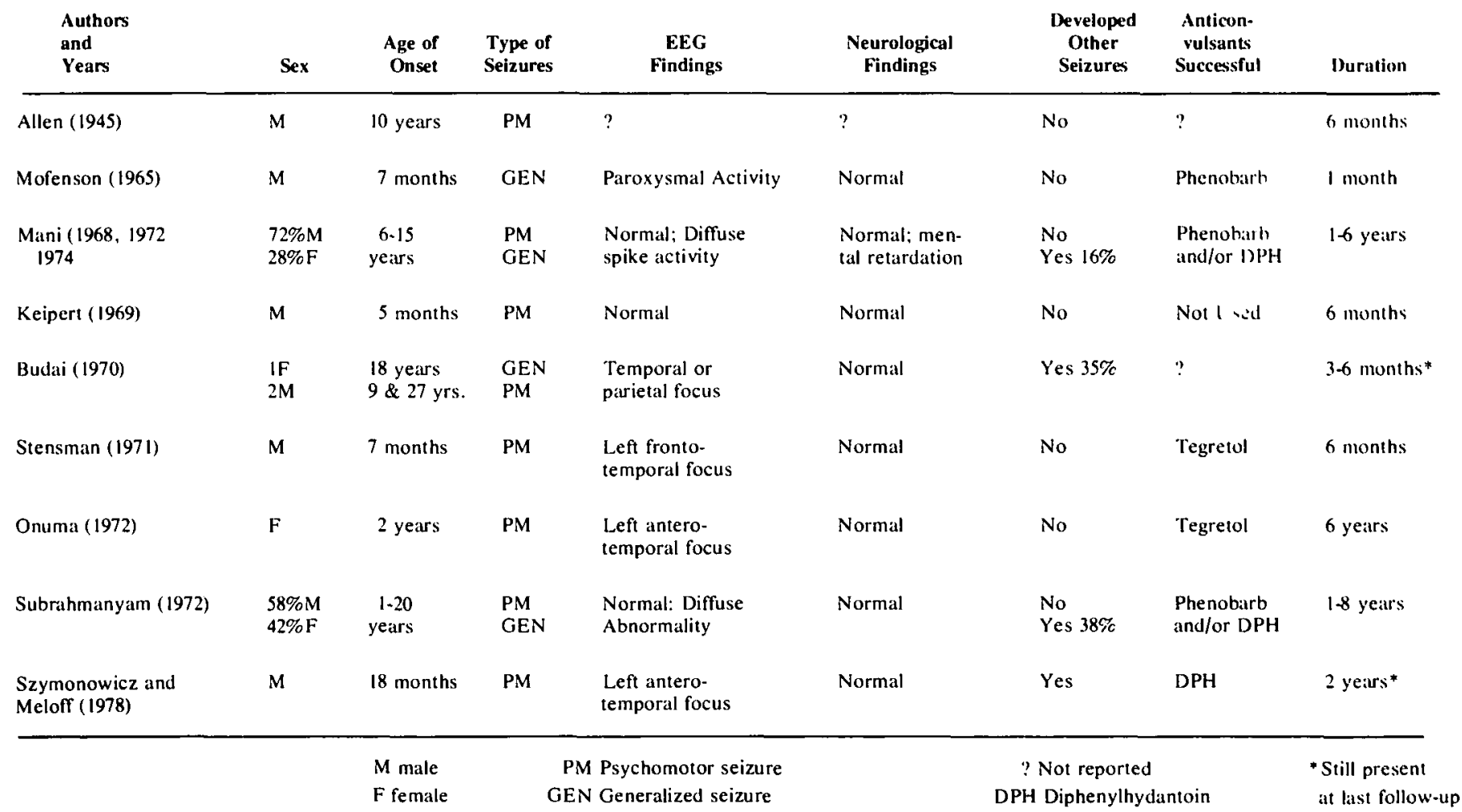




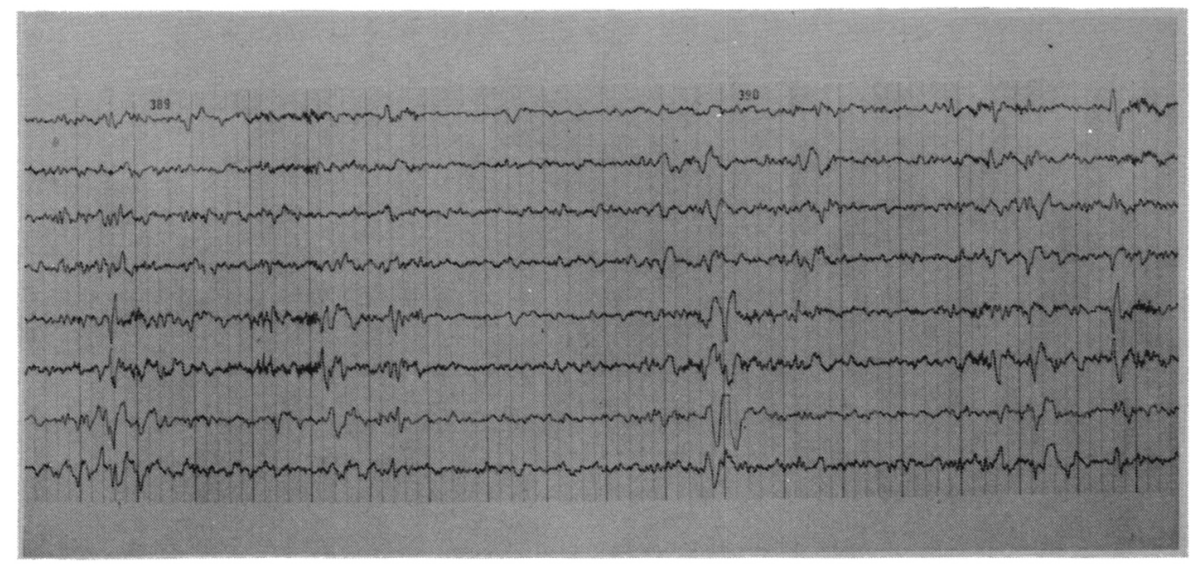

Figure $/ B$-Upper four tracings are from right hemisphere. Lower four tracings are from left hemisphere. Intravenous Brietal induced spike and wave activity which is arising from the left antero-temporal and mid-temporal region.

show a temporal lobe focus. Other investigations are normal.

Treatment need not be as drastic as the suggestions that the child not bathe at all or that he be periodically dry cleaned. One alternative is bathing in water with a temperature less than $37^{\circ} \mathrm{C}$ or sponge-bathing. Another alternative is anticonvulsant therapy. Carbamazepine (Tegretol) (Stensman and Ursing, 1971; Onuma et al., 1972), phenobarbital and or diphenylhydantoin (Mofenson et al., 1965; Mani et al., 1968, 1972, 1974; Subrahmanyam, 1972) and diphenylhydantoin alone, in our case have reduced the frequency of seizures. The evaluation is difficult because this form of epilepsy seems to disappear readily without treatment (Mani et al., 1968; Mofenson et al., 1965; Keipert 1969).

The prognosis seems favorable. In some cases the seizures lasted only a few months (Allen, 1945; Mofenson et al., 1965; Keipert, 1969; Stensman and Ursing, 1971), while in others they disappeared within one to six years of the initial presentation (Mani et al., 1968, 1972, 1974; Onuma et al., 1972; Subrahmanyam, 1972). This is similar to benign focal epilepsy in children which has recently been recognized (Lerman, 1975; Beaussart, 1972; Blom et al.. 1972; Lombroso, 1967). Non-reflex epilepsy developed in $38 \%$ of Subrahmanyam's series (1972), in $16 \%$ of Mani's series (1974), in one case of Budai's series (1970) and in our case.

This type of reflex epilepsy has occurred in New Zealand, Australia, the United States, Sweden Roumania, Japan and India. It is reported most frequently from India particularly from Mysore State. In India, hypocalcemia and rickets are an important cause of seizures in children six months to two years old (Bhagat et al., 1968). Mani et al. $(1968,1972,1974)$ and Subrahmanyam (1972) do not comment about hypocalcemia or rickets in their patients. They do, however, suggest that the use of very hot water $\left(40^{\circ}-50^{\circ} \mathrm{C}\right)$ poured over the head may play an important part in the increased incidence in Mysore State.

The available clinical and investigational data suggest that this type of epilepsy is precipitated by a complex tactile and temperaturedependant stimulus. The EEG findings indicate that there is a temporal lobe abnormality in these patients. It is possible that this type of reflex epilepsy involves the temporal lobe and perhaps hypothalamic structures involved in temperature regulation.

\section{REFERENCES}

ALLEN, 1. M. (1945). "Observations on bases of reflex epilepsy", New Zealand Medical Journal 44, 135.
ALLEN, I. M. (1956). "The emotional factor and the epileptic attack", New Zealand Medical Journal 55, 297.

BEAUSSART, M. (1972). “Benign epilepsy of children with rolandic (centro-temporal) paroxysmal foci", Epilepsia 13, 795.

BHAGAT, M. P., KATIE, N. M. and DESAI, A. D. (1968). "Febrile Convulsions: A clinical and electroencephalograhpic study", Proceedings of the Australian Association of Neurology 5, 577

BINGEL, A. (1958). "Reading epilepsy", Neurology (Minneapolis) 7, 752 .

BLOM, S., HEIJBEL, I. and BERGTORS, P. G. (1972). "Benign epilepsy of children with centro-temporal EEG foci - prevalence and follow-up study of 40 patients" Epilepsia 13, 609.

BUDAI, R. and POPESCU-TISMANA, G. (1970). "Reflex epileptic paroxysms of cutaneous origin" Studii si Cercetari de Neurologie 15, 45.

DAUBE, J. R. (1965). "Sensory precipitated seizures: A review", Joural of Nervous and Mental Disease 141, 524.

GUMBERT, J. and PAUL, R. (1971). "Activation of the electroencephalogram with intravenous brietal (methohexitone): Findings in 100 cases", Journal of Neurology, Neurosurgery and Psychiatry 34, 646.

HALL, M. (1833). Philosophical Transactions 123,635 .

HANSOTIA, P. and BERENDES, J. (1972). "Methohexital hypnosis in electroence. phalography", Disease of the Nervous System 33, 451 .

INGVAR, D. H. and NYMAN, G. E. (1962). "Epilepsia arithmetics: A new psychological trigger mechanism in a case of epilepsy", Neurology (Minneapolis) 12 , 282.

KEIPERT, J. A. (1969). "Epilepsy precipitated by bathing: water-immersion epilepsy", Australian Pediatric Journal 5, 244.

LERMAN, P. (1975). “Benign focal epilepsy of Childhood", Archives of Neurology 32. 261.

LOMBROSO, C. (1967). "Sylvian seizures and midtemporal spike foci in children". Archives of Neurology 17, 52.

MANI, K. S., GAPALAKRISHMAN, P. N., VYAS, J. N. and PILLAI, M. S. (1968). "Hot water epilepsy - a peculair type of reflex epilepsy: a preliminary report", Neurology (Bombay) 16, 107.

MANI, K. S., MANI A. J., RAMESH, C. K. and AHUJA, G. K. (1972). "Hot water epilepsy: clinical and electroencephalographic features: study of 60 cases". Neurology (Bombay) 20, 237.

MANI, K. S., MANI, A. J. and RAMESH, C. K. (1974). "Hot water epilepsy -- a peculiar type of reflex epilepsy: clinical and electroencephalographic features in 108 cases", Transactions of the American Neurological Association 99, 224. 
MANI, K. S., MANI, A. J., RAMESH, C. K. and AHUJA, G. K. (1974). "Hot water epilepsy: clinical and electroencephalographic features:, In Suberana, A., Espadaler. J. M. (Eds.) International Congress Series, Amsterdam: Excerpta Medica $319,198$.

MELOFF, K. (1971). "Seizures and fever", Postgraduate Medicine 50, 107.

MILLICHAP, J. G. (1968). "Febrile convulsions" New York: MacMillan.
MOFENSON, H. C., WEYMULLER, C. A. and GREENSHER, J. (1965). "Epilepsy due to water immersion", Journal of the American Medical Association 191, 600.

ONUMA, T. et al. (1972). "A case of epilepsy precipitated by bathing". Clinical Neurology ('Tokyo) 12, 386 .

SHERWIN, I. and HOOGE, J. P. (1973) "Comparative effectiveness of natural sleep and methohexital", Neurology (Minneapolis) $23,973$.
STENSMAN, R. and URSING, B. (1971). "Epilepsy precipitated by hot water immersion". Neurology (Minneapolis) 21. 559.

SUBRAHMANYAM, H. S. (1972). "Hot water epilepsy", Neurology (Bombay) 20. 241.

WILDER, B. (1971), "Electroencephalogram activation in medically intractible epileptic patients", Archives of Neurology 25, 415. 